IRA International Journal of Management \& Social Sciences ISSN 2455-2267

Vol. 14, Issue 02 (Special Issue) pg. 17-27.

International Conference on Wellbeing: Lifespan Perspectives छo Practices for Sustainable

Communities, 2019.

\title{
Employee Wellbeing - Are Organizations Addressing it the Correct Way?
}

Anamika Chakraborty

Research Scholar, Department of Business Administration, Gauhati University, India.

Dr Monoshree Mahanta

Associate Professor, Department of Business Administration, Gauhati University, India.

DOI: $10.21013 /$ jmss.v14.n2sp.p3

(C) Authors.

Type of Review: Peer Reviewed under the Responsibility of the conference's Scientific Committee.

Disclaimer: The copyright to this work is retained by the authorship. This work contains the opinions 6 views of the authorship solely and the same are not the views or opinions of the IRA. IRA disclaims of any harm or loss caused due to the published content to any party. 


\section{ABSTRACT}

Work is a fundamental aspect of life. Employees spend much of their waking hours at work with an average of around 9 hours per day and 48 hours per week. With the amount of time the workforce spends working, it is not surprising that work relates significantly to overall well-being and life satisfaction. One key aspect of wellbeing that work affects is stress and it has several significant health-related consequences. With the high turnover in most organizations and with many organizations giving excellent employee benefits, it has become imperative to provide employees with reasons to stay.

Many researchers have linked performance with wellness. Studies have indicated that there are many high levels of organizational productivity loss which are directly linked to workplace stress and a lack of employee wellness. Employees who aren't well physically or mentally won't be able to work to their full potential. Wellbeing affects an employee's ability to creatively solve problems. It also influences their attitude to work, and their relationship with co-workers and it affects their health as well. It is a key issue that organizations are trying to address. Large numbers of employers have adopted workplace wellbeing strategies and are relating them to HR objectives. The focus on employee wellbeing has never been more crucial than it is today.

The question is - What is the goal of wellbeing programs in organizations? How do employees perceive such programs? Is it able to address both the male and female workforce? Are the programs effective? Is it backed by data? In our study, we try to answer these questions. Our empirical study seeks to identify the stress factors for employees and assess the wellbeing programs of organizations to find out whether they are able to address the stress-inducing factors. We also try to find the scope of HR analytics in making the wellbeing programs effective, thus enhancing employee wellbeing.

Keywords- Employee wellbeing, stress, HR analytics

\section{Introduction}

Work is a fundamental aspect of life. Employees spend much of their waking hours at work with an average of around 9 hours per day and 48 hours per week. With the amount of time the workforce spends working, it is not surprising that work relates significantly to overall well-being and life satisfaction. One key aspect of wellbeing that work affects is stress and it has several significant health-related consequences. Work-related stress is associated with increased absenteeism, reduced efficiency at work and large costs for society (Henderson, Glozier, \& Elliott,2005; Kalia, 2002; Sultan-Taïeb, Chastang, Mansouri, \& Niedhammer, 2013). Further, chronic stress can lead to many stress-related disorders. Stress has been associated with a range of adverse health outcomes, such as anxiety and depression (Fawzy \&Hamed, 2017; Melchior et al., 2007; Tennant, 2001), coronary disease (e.g. Li, Zhang, Loerbroks, Angerer, \& Siegrist, 2014), and sleep problems (e.g. Faber \& Schlarb, 2016).

Studies have indicated that there are many high levels of organizational productivity loss which are directly linked to workplace stress and a lack of employee wellness.

Wellbeing is a key issue that organizations are trying to address. The highlights of the study by Assocham on wellness titled, 'Corporate Wellness Program: Benefits to Organization and Economy,' covering a wide range of industries are -

- For every rupee that is spent on employee wellness, employers get a saving of Rs.132.33 as savings on absenteeism costs, and Rs. 6.62 back as reduced health care costs.

- $83 \%$ of the respondents of the study are willing to contribute a percentage of their salary in companysponsored wellness programs.

- In the IT/ITeS sector, 93\% of the employees were of the view that a company-sponsored wellness program will motivate them, whereas the remaining $7 \%$ felt depressed about healthcare programs.

- Similarly, $60 \%$ in the media industry, $75 \%$ in FMCG, $84 \%$ in financial services, consider such programs to be motivating, whereas the remaining did not express any interest in participating in wellness programs.

- Several top 500 Indian companies undertaking Corporate Social Responsibility (CSR) initiatives offer healthcare programs and facilities in areas around their factories, yet $42 \%$ of them ignore the health of their employees. 
- Despite the availability of preventive health care benefits, most of the respondents are unable to take advantage of the same. This is due to a lack of awareness of the benefits or hesitation in asking for clarifications about them.

- $48 \%$ of the respondents stated that their company offers wellness programs, of which $62 \%$ are of the belief that the program needs improvement.

- Of the $52 \%$ who said that their organization offers no wellness program, $51 \%$ admitted that if in the future, their company does initiate a wellness program, they will participate in the same.

This study provides evidence that there exists a gap between the requirement and design and implementation of the wellness programs of organizations even though large numbers of employers have adopted workplace wellbeing strategies and are relating them to HR objectives. Most organisations, however, take a reactive, rather than proactive, approach to health and well-being.

\section{Objectives of the Study}

This study addresses the issues highlighted in the previous section and attempts to -

(i) Understand organizations' perspectives on employee wellbeing

(ii) Understand employee perception towards their organization's wellbeing programs

(iii) Assess the ability to handle the level of stress in employees; causes of stress for employees, and stress symptoms.

Accordingly, we have put forth the following research questions:

- What is the goal of wellbeing programs in organizations?

- How do employees perceive such programs?

- What are the challenges faced by organizations to implement these programs?

$\circ$ Are there any metrics used to evaluate the programs?

\section{Literature Review}

Stress is the psychological and physical state that results when the resources of the individual are not sufficient to cope with the demands and pressures of the situation. Thus, stress is more likely in some situations than others and in some individuals than others (Michie, 2002). Day to day happenings like arguments, work deadlines or being late for an appointment causes stress in almost everyone. These stressors can have a strong impact on well-being (Almeida, 2005; Schönfeld, Brailovskaia, Bieda, Zhang, \& Margraf, 2016; Thoits, 2010).

Wellbeing, over the years, has acquired a broader meaning and involves physical, mental, emotional and social wellbeing rather than just the absence of disease (de Stefania, 2014). Well-being can be broken down into emotional, social, and psychological well-being (Diener, Napa Scollon, \& Lucas, 2009; Diener, Suh, Lucas, \& Smith, 1999; Ryff, 1989). Emotional well-being refers to feelings of happiness and (life) satisfaction. Psychological well-being refers to living a rich life, in which one's abilities are taken into account. Social wellbeing refers to the feeling that one values and is valued by the society in which one lives. The inability of the employee to balance the equally challenging demands of their work and personal life has contributed to the escalating stress and conflict of today's workforce (Edwards \& Rothbard, 2000). This leads to significant rise in stress-related health problem, which translates to financial cost both to the employer as well as the government (Johnson, Duxbury \& Higgins, 1997, Frone, Russell, \& Cooper, 1997).

Cooper and Marshall (1978) identified the potential sources of occupational stress as:

- Factors intrinsic to the job (work overload or underload, shift work, long hours, and quality of the physical working environment);

- Role in the organization (role ambiguity, role conflict, the degree of responsibility for others)

- Relationships at work (with superiors, colleagues, subordinates);

- Job insecurity and career development;

- Organizational structure and climate (lack of participation and effective consultation, poor communication, ambiguous work environment, individual cultural incongruence);

- Home/work interface 
It is well established in the literature that employees with a high level of psychological well-being are better, more committed, and more productive than employees with a low level of psychological well-being (Wright and Bonett 2007, Wright and Cropanzano 2004).

\section{Methodology}

\section{Sample \& Data Collection}

This study is entirely based on primary data collected from two samples. The first sample comprised of HR professionals and senior management of 10 organizations belonging to IT, Financial Services, Automotive, Power, Media, Government sectors. The interview was conducted telephonically and the questions were structured.

The second sample comprised of 59 employees belonging to organizations such as Congnizant, TCS, Infosys, National Insurance, Yes Bank, Axis Bank, Ford, Berger Paints, CavinKare and a few others. The survey was conducted online and physically using a structured questionnaire capturing the demographic details, perception towards wellbeing programs, causes of workplace stress, ability to handle workplace stress.

\section{Sample Profile}

Out of the 59 respondents, 23 were female and 36 male and from various age groups. The job experience range was from less than 5 years to above 20 years. The sample belonged to different organizations across various sectors as given in the figures below.

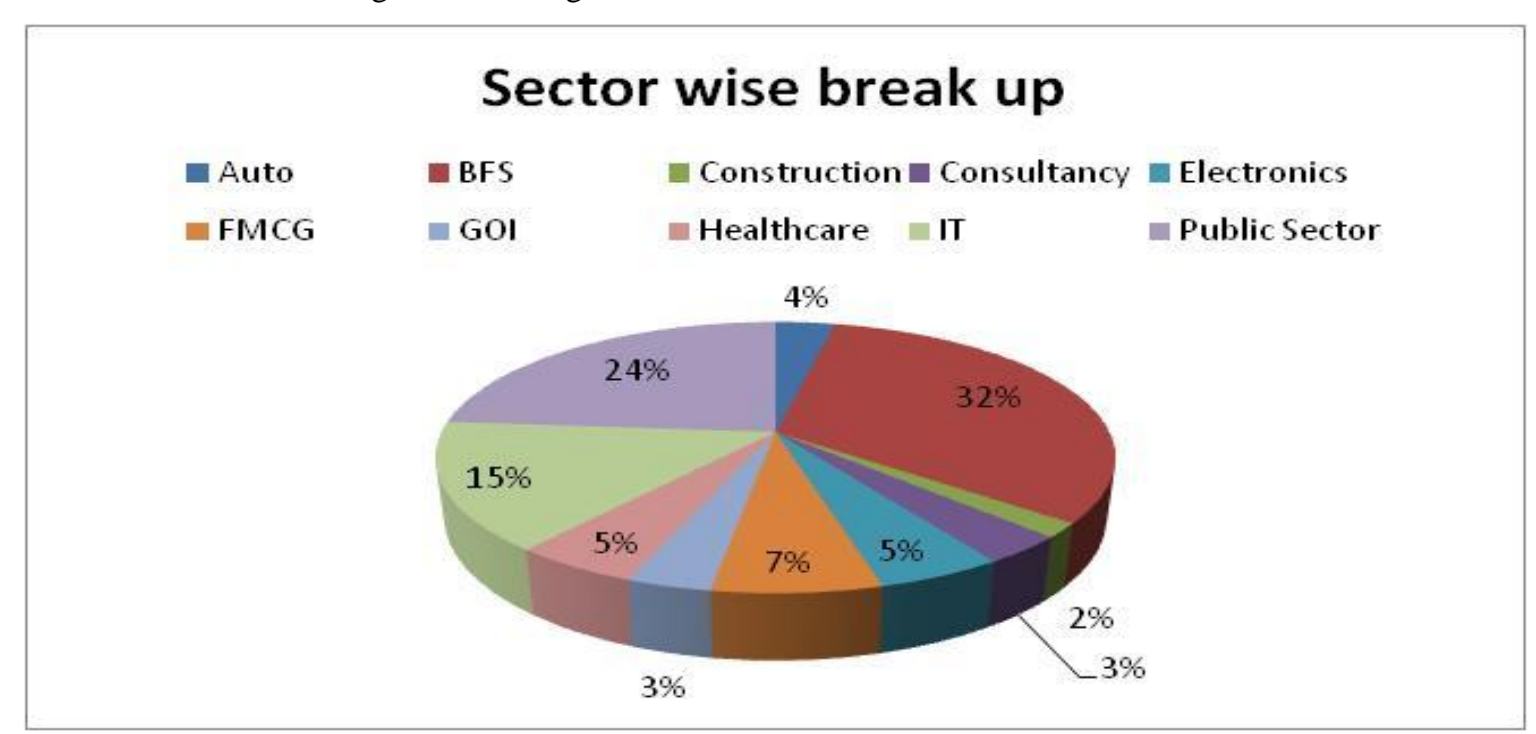

The age of the respondents was grouped as follows-

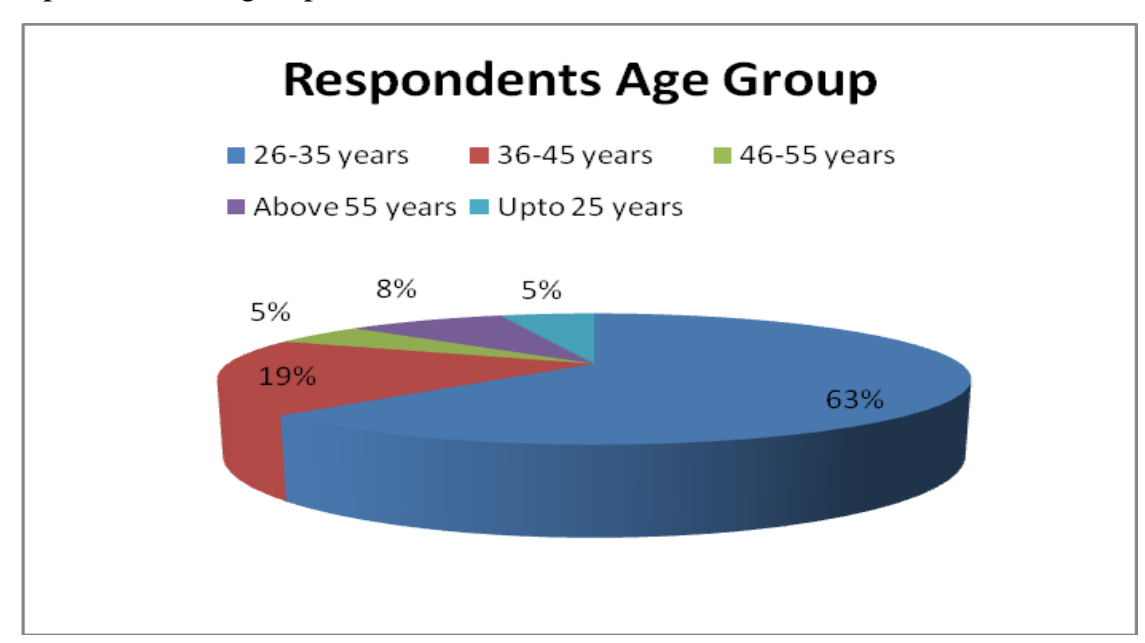




\section{Job Experience}

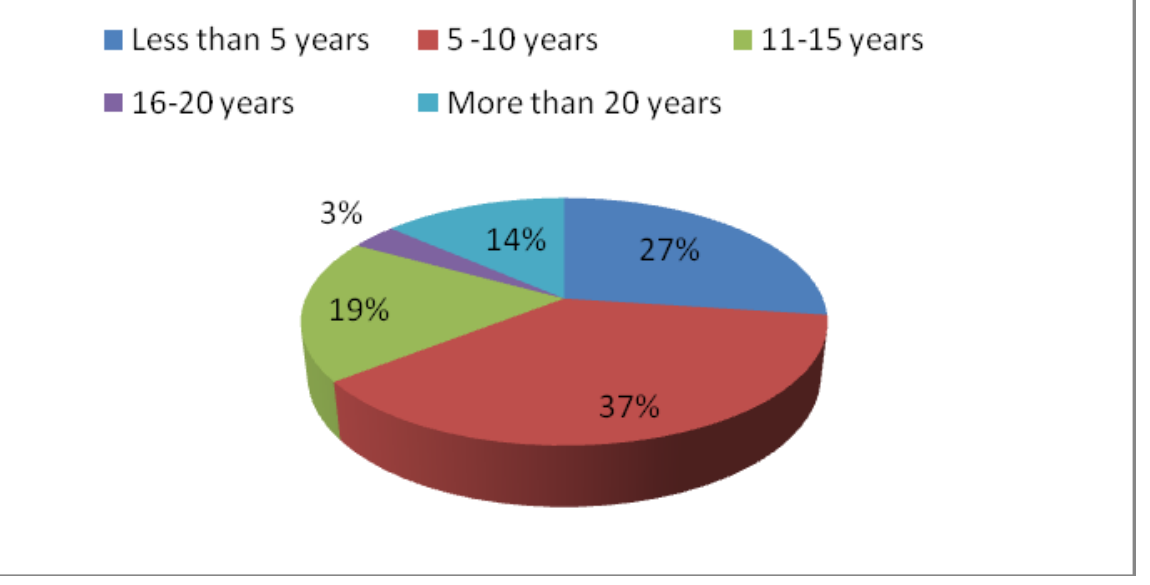

\section{Measures}

A ten-item seven-point Likert scale adapted from the Job Stress Survey instrument developed by AIS (The American Institute of Stress) has been used to assess how well employees handled workplace stress. The other questions of the survey were from the literature study (Cooper and Marshall, 1978).

\section{Data Analysis}

Content analysis, Averages, Percentages has been used for data presentation and analysis.

\section{Analysis and Findings}

\subsection{Wellbeing Practices Across Sectors}

For our study, we interviewed the HR professionals and senior management of organizations to learn the wellbeing practices of that company. We have grouped the organizations sector-wise.

\section{IT Sector}

Company 'A' - In 'A', there is a platform provided to the employees, where they can form clubs based on their hobbies and interests and take up activities together. They also undertake CSR activities, such as beach cleanup, teaching underprivileged children, visiting old age homes etc.

To address the health aspect of wellbeing, ' $A$ ' provides for doctors to visit each development centre at-least once a week. Sessions are also conducted by healthcare specialist on a particular health issue every quarter. Gyms and exercise areas are also provided in many of the centres where the number of employees is high. These benefits are free of cost for the employees.

Keeping the emotional and mental wellbeing part in mind, 'A' also has arranged for counsellors to visit biweekly and they have also developed an in-house portal whereby if the employee wants to find help online, they can use the one to one helpline. They also call speakers from outside to motivate the employees and conduct a workshop on stress management. 'A' also has tie-ups with crèches for its employees, whereby the employees get concessions.

'A' has guest houses in a few tourism destinations, which are provided to the employees at reduced rates, also the employees of the organization can avail discounts and reduced rates in some specific hotels through which have tie-ups with 'A'. There are many other activities such as retreats etc, which are conducted by the individual departments.

\section{Company B}

In 'B', the wellbeing of the employees comes under an initiative known as Health and Life Enrichment. In each campus, they have doctors available 24 hours on all working days. Counsellors are available once a week. Sessions are also held for emotional and mental wellness.

They have tie-ups with healthcare groups and hospitals through which employees can get vaccinations and health check up done at nominal rates. 
'B' also has employee care centres or vacation homes, which the employees can avail if they are sent on deputation, training or are on vacation etc. to those locations Yoga sessions and other sessions such as on parental support etc are organized regularly.

The employee safety is looked after by the administration.

\section{Company C}

' $\mathrm{C}$ ' has a tie-up with a health and fitness app and the app is customized for its employees and they can chat with the fitness experts and instructors regarding their health issues. Medical camps and eye check-ups are arranged at some of the office locations of company ' $\mathrm{C}$ '. They also arrange for counsellors for their employees and have tie-ups for health check-ups.

A one-day outing is arranged for the employees to rejuvenate and town-halls are arranged regularly to motivate and reward the employees.

' $\mathrm{C}$ ' also has a social outreach club and green club whereby the employees can form groups as per their interest and work for social welfare and a clean environment.

\section{$\underline{\text { Automotive Sector }}$}

\section{Company D}

The organization doesn't have a defined and structured wellbeing program. But wellbeing of employees is encouraged through the employee policy itself. For example, employees are encouraged to take leaves and leaves are not carried over to the next year. The senior management and leadership team meets to decide on the wellbeing strategies or programs to be conducted and the employees have a say on the planned activities. Most of the programs are employee initiated and thus participation is high.

They also have yoga classes once in 6 months and are encouraging employees to remain healthy and fit through bringing in gamification of fitness. There is a team-wise acknowledgement for fulfilling fitness goals.

Retreats are conducted twice yearly and they have team dinners and lunches regularly.

\section{Banking and Financial Sector}

\section{Company E}

' $E$ ' has tie-ups with the employee health insurance provider to provide for health check-ups every four years.

They have Leave Travel Allowance, whereby if the employee goes on vacation taking leave from work than the employee and his/her dependents travel expenses are reimbursed by the organization.

The employees of the organization have formed an Employee Co-operative society and ' $E$ ' provides space and sponsors the activities organized by it. The activities organized include games and other recreational events like picnics, art competitions, family get together etc. Every division is also sanctioned funds for employee welfare expenses.

'E' provides financial, health and wellness training to its retiring employees. Their main training centre has yoga and gym facility but offices in other locations don't have these facilities.

\section{Company $\mathbf{F}$}

'F' provides an annual Health check up to all its employees. They also organize various events to de-stress the employees regularly. As for example, every quarter employees along with their families get together and lunches or dinners are organized. Matches such as football, cricket, and badminton are held every quarter.

They have a monthly connect where festival or social oriented themes are discussed and the birthday or an anniversary of the employee falling on that month is celebrated. ' $\mathrm{F}$ ' also organizes domestic and international vacations for high performing employees every quarter.

\section{Company G}

In 'G', senior-level employees are provided health check-up every 2 years. They have stress management workshops as part of the training program which every employee has to undergo.

The wellbeing activities of the organization are undertaken centrally or circle-wise, where each circle consists of a bigger branch office and the other nearby smaller offices. They have a recreation club, which discussions and 
talks such as on work life balance. The circle office organizes for team lunches and events for its employees such as ethnic day, rangoli etc.

They have a foundation through which the CSR activities are done.

\section{Government Sector}

\section{Company $\mathbf{H}$}

For the Government of India employees, the Central Government has a Central Government Employee Health Scheme [CEGS], whereby the medical treatments are subsidised in Government Hospitals and a panel of private hospitals. The medical tests undergone are also reimbursed.

For senior ranked officers above 40 years, they have an annual health check up plans.

The employees can avail Leave Travel Concession every year, through which they can get to and fro fares to their vacation destination from their home town reimbursed. They also have guest houses at a few locations.

For the retiring employees, pre-retirement counselling is done; this is a tie-up with Help Age India.

' $\mathrm{H}$ ' also has various social outreach programs.

\section{Media Sector}

\section{Company I}

'I' provides for recreation facility to its employees through their recreation club, where games and other activities take place. The employees are also provided with annual health check-ups through tie-ups with hospitals.

'I' has guest houses in some locations and the employees can avail the same free of cost. Every year they organize picnics and retreats for their employees.

\section{Power Sector}

\section{Company J}

' $J$ ' provides its employees with the in-house medical facility and also has tie-up with major hospitals for the annual health check-up of its employees. They have a gym and recreation centre inside the premises. Sessions on stress management are held regularly and counselling services are also provided for the employees.

' $\mathrm{J}$ ' conducts outbound trips twice a year for all its employees to rejuvenate and de-stress them.

A third party vendor has tie-up with ' $J$ ' to provides its employee's services such as bill payments, tickets booking etc.

\subsection{Challenges Faced by Organizations to Implement Wellbeing Practices}

During the interview, the HR personnel were asked to identify the challenges faced by them to implement the wellbeing practices in their organization. The sector-wise challenges are summarised below:

\section{IT Sector -}

- Attendance to the yoga sessions or workshops for stress management are low

- Employees are interested only in those areas of wellbeing which affect them at the present

- If health or medical data is asked to be shared, the employees are apprehensive

- The employees don't see the workplace as an area to learn to about wellbeing and stress management, they feel these to be a waste of their time

- Managers aren't willing to nominate subordinates for the activities, as they feel that this will hamper productivity

\section{Financial Finances Sector -}

- Most of the facilities are provided at the head quarters or the main office

- Awareness about the facility provided to the employees is very low

- Employees are only interested in activities which are linked to their performance

Government Sector -

- Only the mandatory wellbeing programs are implemented

- Due to the paper work and approvals required to conduct activities, the managers hesitate to take the initiative 


\section{Automotive Sector -}

- The wellbeing programs and processes are not streamlined.

- Dependent on the senior management or leadership for implementation

- Team acknowledgements can lead to further competition and stress among the employees

\subsection{Metrics Used To Evaluate The Programs}

All the organizations interviewed for the purpose of the study, have employee surveys and feedback processes in place. The surveys are generally conducted once a year and feedbacks are collected after each wellbeing session. But except organization 'B', they don't analyse the data.

This is mostly due to lack of HR analytics expert in the organization and also due to lack of time. Most of the organizations follow the leading organizations of the particular sector, to form their policy.

\section{Survey Findings}

\subsection{Employee Perception of Wellbeing Programmes}

To understand employee perception of their organization's wellbeing programmes, we asked them about the facilities provided for their wellbeing and whether they utilized those facilities. $50 \%$ of the respondents utilized the facilities while $29 \%$ did not use the facilities. The rest $21 \%$ were not aware of any facility related to employee wellbeing.

We listed around seven facilities that are related to well being and tried to find out how far employees used these facilities provided by organizations. The facilities listed out were related to health, vacation and holiday trips (V\&T), stress management (SM), recreation, flexible timing, social support at workplace (SSW), yoga/ aerobics/gym facility (YAG). The responses to the dichotomous question of whether their organization provided the listed facilities and whether they utilized them are summarized in Table 1a.

Table 1a: Wellbeing Facilities and Employee Perception (as Counts)

\begin{tabular}{|c|c|c|c|c|c|c|c|c|c|c|c|c|c|c|}
\hline $\begin{array}{l}\text { Employee } \\
\text { Wellbeing } \\
\text { Facilities }\end{array}$ & \multicolumn{2}{|c|}{ Health } & \multicolumn{2}{|c|}{ V\&T } & \multicolumn{2}{|l|}{ SM } & \multicolumn{2}{|c|}{ Recreation } & \multicolumn{2}{|c|}{$\begin{array}{l}\text { Flexible } \\
\text { Timing }\end{array}$} & \multicolumn{2}{|c|}{ SSW } & \multicolumn{2}{|c|}{ YAG } \\
\hline \multirow{2}{*}{ Utilized } & \multicolumn{2}{|c|}{ Provided } & \multicolumn{2}{|c|}{ Provided } & \multicolumn{2}{|c|}{ Provided } & \multicolumn{2}{|c|}{ Provided } & \multicolumn{2}{|c|}{ Provided } & \multicolumn{2}{|c|}{ Provided } & \multicolumn{2}{|c|}{ Provided } \\
\hline & Yes & No & Yes & No & Yes & No & Yes & No & Yes & No & Yes & No & Yes & No \\
\hline Yes & 12 & 6 & 16 & 8 & 2 & - & 6 & 2 & 6 & 3 & 5 & 2 & 3 & 3 \\
\hline No & 8 & 20 & 7 & 17 & 3 & 19 & 5 & 30 & 1 & 31 & 5 & 31 & 8 & 28 \\
\hline Total count & 20 & 26 & 23 & 25 & 5 & 19 & 11 & 32 & 7 & 34 & 10 & 33 & 11 & 31 \\
\hline
\end{tabular}

The findings are further analyzed and reported as the percentage of respondents in Table $1 \mathrm{~b}$.

Table 1b: Employee Wellbeing Facilities and Employee Perception (in Percentage)

\begin{tabular}{|l|l|l|l|}
\hline Wellbeing facilities/ Programmes & $\begin{array}{l}\text { Provided } \\
\text { 'Yes' }\end{array}$ & $\begin{array}{l}\text { Provided } \\
\text { 'No' }\end{array}$ & $\begin{array}{l}\text { Utilized } \\
\text { 'Yes' }\end{array}$ \\
\hline Health awareness/ Check-up & $43 \%$ & $57 \%$ & $60 \%$ \\
\hline Vacation and holiday trips & $48 \%$ & $52 \%$ & $70 \%$ \\
\hline Stress management workshop/ programmes & $21 \%$ & $79 \%$ & $40 \%$ \\
\hline Recreation centre & $26 \%$ & $74 \%$ & $54 \%$ \\
\hline Flexible timing & $17 \%$ & $83 \%$ & $86 \%$ \\
\hline Social support at the workplace & $23 \%$ & $77 \%$ & $50 \%$ \\
\hline Yoga classes/ aerobics/gym facility & $26 \%$ & $74 \%$ & $27 \%$ \\
\hline
\end{tabular}

The majority (column 3 of Table $1 \mathrm{~b}$ ) of the respondents perceive that the listed facilities related to employee wellbeing are not provided by their organization. The percentage of respondents having this perception was more than $70 \%$ for 5 facilities (stress management, recreation centre, flexible timing, social support at workplace and yoga classes/ aerobics/gym facility). Out of those who perceived that the facilities were provided, modest percentages $(50 \%-70 \%)$ of respondents have used four facilities (health, V\&T, 
recreation, SSW) out of the seven. Further, a very low percentage (below 25\%) of respondents perceived that facilities such as stress management programmes/ workshops (21\%), flexible timing (17\%) are provided by their organizations. This leaves a lot of scopes for organizations to improve this perception.

\subsection{Stress Perception}

As mentioned earlier a ten-item seven-point Likert scale adapted from Job Stress Survey instrument developed by AIS (The American Institute of Stress) has been used to assess how well employees handled workplace stress. The responses to each item were summed up to get the Total Job Stress Score. Scores between10-21 indicate that job stress is handled well; between 22- 41 indicates that job stress is handled moderately well; between 42-70 indicates that employees are facing problems at the workplace which need to be resolved.

On the basis of the above-mentioned classification scheme, it has been found from the average score $(=32.15)$ that on an average, the respondents had been able to handle job stress moderately well. Table $2 \mathrm{a} \& 2 \mathrm{~b}$ shows the distribution of the respondents on the basis of stress scores and demographic variables such as gender, age and marital status.

Table 2a: No. of Respondents according to Ability to handle Stress and Demographic Variables

\begin{tabular}{|l|l|l|l|l|l|l|l|l|l|}
\hline \multirow{2}{*}{ Scores } & Total Count & \multicolumn{3}{|l|}{ Gender } & \multicolumn{3}{l|}{ Age-group (years) } & \multicolumn{2}{l|}{ Marital status } \\
\cline { 3 - 10 } & & Male & Female & $<25$ & $26-35$ & $36-45$ & $>=46$ & Married & Unmarried \\
\hline $10-21$ & 12 & 4 & 8 & 0 & 6 & 4 & 2 & 10 & 2 \\
\hline $22-41$ & 33 & 25 & 8 & 3 & 23 & 4 & 3 & 19 & 14 \\
\hline$>=42$ & 13 & 6 & 7 & 0 & 8 & 2 & 3 & 7 & 6 \\
\hline Total & $\mathbf{5 8}$ & $\mathbf{3 5}$ & $\mathbf{2 3}$ & $\mathbf{3}$ & $\mathbf{3 7}$ & $\mathbf{1 0}$ & $\mathbf{8}$ & $\mathbf{3 6}$ & $\mathbf{2 2}$ \\
\hline
\end{tabular}

Table 2b: Percentage of Respondents according to Demographics and Stress scores

\begin{tabular}{|c|c|c|c|c|c|c|c|c|}
\hline \multirow[t]{2}{*}{ Score Range } & \multicolumn{2}{|c|}{ Gender } & \multicolumn{4}{|c|}{ Age-group (years) } & \multicolumn{2}{|c|}{ Marital status } \\
\hline & Male & Female & $<25$ & $26-35$ & $36-45$ & $>=46$ & Married & Unmarried \\
\hline & $11.4 \%$ & $35 \%$ & 0 & $16 \%$ & $40 \%$ & $25 \%$ & $28 \%$ & $9 \%$ \\
\hline $22-41$ & $71.4 \%$ & $35 \%$ & $100 \%$ & $62 \%$ & $40 \%$ & $37.5 \%$ & $53 \%$ & $64 \%$ \\
\hline$>=42$ & $17.2 \%$ & $30 \%$ & 0 & $22 \%$ & $20 \%$ & $375 \%$ & $19 \%$ & $27 \%$ \\
\hline
\end{tabular}

As can be seen from Table 2a, female employees are equally distributed across the three groups viz., job stress is handled well ( 8 out of 23), job stress is handled moderately well ( 8 out of 23) and problems at the workplace which need to be resolved (7 out of 23). While the majority (71\%) of the male employees are able to handle job stress moderately well (Table $2 \mathrm{~b}$ ) more female employees (30\%) face workplace problems compared to male employees (17\%).

It has been found that all the employees who have recently entered the workplace are able to handle workplace stress moderately well. Majority of the employees (62\%) in the age group 26-35 years are able to handle job stress moderately well; while $40 \%$ of those in the age group 36-45 years are able to handle job stress moderately well and; $38 \%$ in the age group 46 years \& above are able to handle job stress moderately well. Interestingly more employees (38\%)in the 46 years \& above age group are found to be facing workplace problems compared to those in the age groups 26-35 years and 36-45 years. Generally, one would expect employees who have been with an organization for long to experience lesser workplace problems, which is contradictory to our finding.

We also found that the majority of employees, both married (53\%) and unmarried (64\%), belonged to the second group i.e., 'could handle workplace stress moderately well'. But more unmarried employees (27\%) faced workplace problems leading to stress compared to the married ones (19\%). Married employees (28\%) handled job stress well compared to unmarried employees (9\%) as indicated in Table $2 \mathrm{~b}$.

\subsection{Stressors at the Workplace}


To find what causes stress at the workplace, respondents were asked to rank five factors out of ten factors which they feel are the most important causes for stress. The factors in order of importance as perceived by employees are given in Table 3 .

Table 3: Stressors at the Workplace

\begin{tabular}{|l|l|}
\hline Rank & Stress Factors \\
\hline 1 & Workload \\
\hline 2 & Repetitive work; Time pressure \\
\hline 3 & Lack of Job Security; Unplanned Work \\
\hline 4 & The absence of career development \\
\hline 5 & Frequent travel \\
\hline
\end{tabular}

Workload has been identified as the most important factor followed by repetitive work, Time pressure and meeting deadlines. The other important factors identified are lack of job security, unplanned work. The absence of career development and frequent travel has also been identified to contribute to job stress. The other factors considered in the scale were 'relationship with supervisors' and 'relationship with peers' but did not feature in the first five ranks.

\section{Conclusion}

From the information captured from the interview, we can conclude that among the organizations studied, the IT sector has incorporated many wellbeings and stress-reducing practices than the other sectors into consideration. This can be due to the high attrition rates in the sector and the high competition among the Indian and foreign organizations. Also, as IT organizations have a presence outside of India, they have to meet the regulations of the host country as well. Company ' $\mathrm{J}$ ' in the power sector also provides many facilities to its employees but these are due to the government regulations of the home country of ' $\mathrm{J}$ '. But many of the wellbeing practices provided by the organizations are not availed by the employees as they are either not aware of it, or they do not see any benefit out of it.

We found that general awareness about wellbeing is lacking in the employees and also, they are not aware of the wellbeing programs of their own organization. This might be due to a lack of communication by the management to the employees. The focus on wellbeing by the organizations also needs to increase. Having a wellbeing program is not enough. Organizations also need to find out if the programs are addressing the concerns of the employees. Metrics need to be used, as things which are measurable can be changed or made better. Most of the organizations, don't measure the effectiveness of the program, even though feedback is collected.

The survey findings indicate that employees require health checkups, work-life balance, stress management classes and flexible timings from their organizations. We believe stress management, as well as work-life balance, are important determinants of employee wellbeing. The management can take these requirements of the employees into consideration and design the wellbeing plans accordingly.

\section{References}

[1]. Cooper, C. L., \& Marshall, J. (1978). Understanding Executive Stress. London: Macmillan.

[2]. de Stefania, S. (2014) Conceptualizing Wellbeing in the Workplace. International Journal of Business and Social Science, 5/12, (07), 118-122; 04; http://ijbssnet.com/journals/vol_5_no_12_november_2014/14.pdf

[3]. Diener, Ed \& Scollon, Christie \& E Lucas, Richard. (2003). The Evolving Concept of Subjective Well-Being: The Multifaceted Nature of Happiness. Advances in Cell Aging and Gerontology. 15. 10.1016/S1566-3124(03)150079.

[4]. Edwards, J., \& Rothbard, N. (2000). Mechanisms linking work and family: Clarifying the relation between work and family constructs. Academy of Management Review, 25(1), 178-199.

[5]. Faber, Jasmin \& Schlarb, Angelika. (2016). The Relation of Sleep, Distress, and Coping Strategies - What Male and Female Students Can Learn from Each Other?. Health. 08. 1356-1367. 10.4236/health.2016.813136.

[6]. Fawzy, Mohamed \& Hamed, Sherifa. (2017). Psychological stress among medical students at Assiut University, Egypt. Psychiatry Research. 255. 10.1016/j.psychres.2017.05.027.

[7]. Frone, Michael \& Russell, Marcia \& Cooper, Mary. (1997). Relation of work-family conflict to health outcomes: A four-year longitudinal study of employed parents. Journal of Occupational and Organizational Psychology. 70. 325 - 335. 10.1111/j.2044-8325.1997.tb00652.x.

[8]. Henderson Max, Glozier Nicholas, Elliott Kevin Holland(2005). Long term sickness absence BMJ 2005; 330: 802 
[9]. Johnson, D., Deterding, S., Kuhn, K. A., Staneva, A., Stoyanov, S., \& Hides, L. (2016). Gamification for health and wellbeing: A systematic review of the literature. Internet interventions, 6, 89-106. doi:10.1016/j.invent.2016.10.002

[10].Johnson, K., Duxbury, L., \& Higgins, C. (1997). Making Work and Lifestyle Initiatives Work: Beyond Best Practices. Prepared for Industry Canada, Ottawa.

[11].Kalia, M. (2002) Assessing the Economic Impact of Stress-The Modern Day Hidden Epidemic. Metabolism, 51, 49-53. http://dx.doi.org/10.1053/meta.2002.33193

[12].Li, Jian \& Zhang, Min \& Loerbroks, Adrian \& Angerer, Peter \& Siegrist, Johannes. (2014). Work stress and the risk of recurrent coronary heart disease events: A systematic review and meta-analysis. International journal of occupational medicine and environmental health. 28. 10.2478/s13382-014-0303-7.

[13].Melchior, Maria \& Caspi, Avshalom \& Milne, Barry \& Danese, Andrea \& Poulton, Richie \& E Moffitt, Terrie. (2007). Work Stress Precipitates Depression and Anxiety in Young, Working Women and Men. Psychological medicine. 37. 1119-29. 10.1017/S0033291707000414.

[14].Michie, S. (2002) Causes and management of stress at work. Occupational and Environmental Medicine 2002;59:67-72;

[15].Ryff, C. D. (1989). Happiness is everything, or is it? Explorations on the meaning of psychological wellbeing. Journal of Personality and Social Psychology, 57(6), 1069-1081

[16].Seth, Manav. (2018, Jan 29) Corporate Wellness Programs in India: Insights from Assocham, Retrieved from https://www.peoplematters.in/article/wellness/corporate-wellness-programs-in-india-insights-from-assocham17379

[17].Diener, E., Suh, E. M., Lucas, R. E., \& Smith, H. L. (1999). Subjective well-being: Three decades of progress. Psychological Bulletin, 125(2), 276-302.

[18].Sultan-Taïeb, Hélène \& Chastang, Jean-François \& Mansouri, Malika \& Niedhammer, Isabelle. (2013). The annual cost of cardiovascular diseases and mental disorders attributable to job strain in France. BMC public health. 13. 748. 10.1186/1471-2458-13-748.

[19].Tennant, C. (2001) Work-related stress and depressive disorders. Journal of Psychosomatic Research, 51, 697704. http://dx.doi.org/10.1016/S0022-3999(01)00255-0

[20].Wersebe, Hanna \& Lieb, Roselind \& Meyer, Andrea \& Hofer, Patrizia \& Gloster, Andrew. (2017). The link between stress, well-being, and psychological flexibility during an Acceptance and Commitment Therapy self-help intervention. International Journal of Clinical and Health Psychology. 18. 10.1016/j.ijchp.2017.09.002.

[21].Workplace Stress. (n.d.). Retrieved from https://www.stress.org/workplace-stress/

[22].Wright, T.A. And Bonett, D.G. (2007), Job Satisfaction and Psychological Well-Being as Non-additive Predictors of Workplace Turnover, Journal of Management, Vol. 33, No. 2, pp 141-160.

[23].Wright, T.A. And Cropanzano, R. (2004), The Role of Psychological Well-Being in Job Performance: A Fresh Look at an Age-Old Quest, Organizational Dynamics, Vol. 33, No 4, pp 338-351. 